\title{
Hispanismes
}

Revue de la Société des Hispanistes Français

$17 \mid 2021$

Murs, barrières, obstacles dans les mondes

hispaniques I

\section{Faisceaux d'isoglosses en République Dominicaine et leurs questions identitaires}

Haces de isoglosas en la República Dominicana y sus cuestiones identitarias Bundles of isogloss in the Dominican Republic and their identity issues

\section{Ariel Osvaldo Tapia Medina}

\section{OpenEdition}

Journals

Édition électronique

URL : https://journals.openedition.org/hispanismes/13307

DOI : 10.4000/hispanismes.13307

ISSN : 2270-0765

Éditeur

Société des Hispanistes Français

\section{Référence électronique}

Ariel Osvaldo Tapia Medina, «Faisceaux d'isoglosses en République Dominicaine et leurs questions identitaires », HispanismeS [En ligne], 17 | 2021, mis en ligne le 01 juin 2021, consulté le 27 janvier 2022. URL : http://journals.openedition.org/hispanismes/13307 ; DOI : https://doi.org/10.4000/ hispanismes. 13307

Ce document a été généré automatiquement le 27 janvier 2022.

\section{cc) (†)}

Les contenus de cette revue sont mis à disposition selon les termes de la Licence Creative Commons Attribution - Pas d'Utilisation Commerciale - Pas de Modification 4.0 International. 


\title{
Faisceaux d'isoglosses en République Dominicaine et leurs questions identitaires
}

\author{
Haces de isoglosas en la República Dominicana y sus cuestiones identitarias \\ Bundles of isogloss in the Dominican Republic and their identity issues
}

Ariel Osvaldo Tapia Medina

À mon cher professeur et directeur Pr. Christian Lagarde. Je vous remercie infiniment de m'avoir transmis tout l'amour pour cette discipline et pour votre accompagnement.

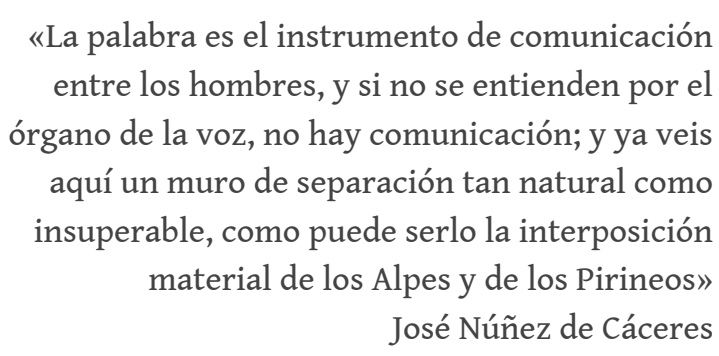

\section{Introduction : à propos de l'identité dominicaine}

Depuis la création de l'État dominicain (1844), trois critères culturels ${ }^{1}$ ont défini l'identité dominicaine: la religion, la langue et l'Histoire officielle ${ }^{2}$. Parmi ces trois éléments la langue espagnole a pris le dessus ${ }^{3}$. C'est ainsi que le récit historique a pris la langue comme un marqueur de l'identité nationale ${ }^{4}$ en la plaçant même au-dessus de la question de la race; elle devient ainsi le signe par antonomase de l'identité nationale ${ }^{5}$. Certes, « les langues n'existent pas en dehors des rapports historiques et sociaux, elles sont le produit des pratiques sociales $»^{6}$, pourtant ces pratiques sociales, en l'occurrence en République Dominicaine, sont vouées à créer des barrières culturelles, 
raciales et politiques. Tout d'abord, parmi les citoyens des différentes régions et ensuite - et notamment - à l'encontre du pays voisin ${ }^{7}$.

2 C'est ainsi qu'elle représente un des sentiments les plus significatifs de la problématique identitaire : la haine de l'autre en soi, que les sociolinguistes catalans ont dénommé autoodis. Ce sentiment, dans le cas de la société dominicaine, se manifeste dans le déni de l'apport culturel de la diaspora africaine ${ }^{9}$ et des rapports entre les différentes variantes de l'espagnol dominicain. Les anciens conflits territoriaux sont les sources de l'exacerbation de ce sentiment. En effet, lors des deux dernières guerres d'indépendance ${ }^{10}$ en République Dominicaine, par exemple, durant celle de 1844 où l'on a essayé d'effacer ou plutôt d'invisibiliser les traits culturels, y compris les substrats linguistiques du monde africain ${ }^{11}$; ou bien lors de la guerre de 1865 , où l'on a en revanche tenté de construire ou de (re)définir une identité linguistique propre aux traits idiosyncrasiques - selon l'imaginaire hégémonique - de la nation dominicaine.

3 Malgré l'hétérogénéité fondatrice et constitutive des identités imaginées des Amériques/Caraïbes ${ }^{12}$, une nouvelle idéologie monoglossique a commencé à s'échafauder à partir des années trente $\mathrm{du} \mathrm{xx}^{\mathrm{e}}$ siècle. Dès lors, cette idéologie a constitué un scenario glossopolitique qui exalte la langue espagnole en tant que paradigme de l'identité linguistique et exclusive du peuple dominicain, au détriment des autres langues issues de la diaspora africaine coloniale. C'est ce que le sociologue dominicain Carlos Andújar Persinal nomme «[...] la amnesia negra o negación del aporte que la negritud hace a nuestra identidad $[. ..] »^{13}$. Ainsi, une entreprise glottopolitique de la sorte, fait émerger une configuration linguistique conflictuelle ${ }^{14}$ telle que l'explique Silke Jansen: "While Dominican identity and self-recognition is directly tied to the Spanish language, Hispanic culture and Catholicism, Haiti is viewed as a cultural antipode whose language, culture and religion are derived not from European, but from African models $»^{15}$. Cette divergence linguistique suscite de multiples barrières comme le reconfirme Silke Jansen :

In highlighting linguistic and cultural differentiation, language ideologies are a means of drawing boundaries between languages or language varieties and of presenting them, by way of iconization, as inherently different in order to justify one's own culture. This is why they can serve as a powerful tool in identity construction through «Othering» ${ }^{16}$.

4 Du fait de la recrudescence de cette dichotomie linguistique, on met alors en avant l'une des fonctions de base de la langue, en l'occurrence, celle qui est la fonction démarcative: « desde el punto de vista sociolingüístico, la lengua tiene dos funciones básicas: una comunicativa, para crear un contacto con otro/s, y una demarcativa, para diferenciarse y para asegurar la propia identidad $»^{17}$.

On constate alors que cette identité peut également être constituée par les idéologies qui privilégient certaines valeurs concrètes sans prendre en compte les autres, à savoir, celles que l'on ne veut pas assumer comme faisant partie de notre identité, et qui constituent en quelque sorte "[...] los fantasmas que nos rodean »" Cette réflexion rend assez bien compte de l'errance fantasmagorique de la culture africaine dans le territoire dominicain.

Or, cette ambiguïté identitaire non seulement se produit intensément au niveau interlinguistique mais également au niveau intralinguistique. En fait, l'espagnol dominicain est constitué par des sous-variantes qui correspondent, plus ou moins, aux trois démarcations géographiques des régions du pays. Dans ce cas, la question 
linguistique est également liée, dans un premier temps, aux questions identitaires de ces sous-variantes et puis, dans un second temps, à l'usage diglossique de celles-ci.

De surcroît, la question identitaire chez les Dominicains devient encore plus complexe si l'on prend en compte les autres identités qui découlent des autres sous-variantes sous-jacentes qui se trouvent à l'intérieur des isoglosses intralinguistiques principales, ou qui, dans certains cas, se trouvent imbriquées dans ces sous-variantes. Il en va de même pour les langues minoritaires/minorisées qui font partie du paysage linguistique dominicain ${ }^{19}$.

8 De ce point de vue, il est capital de faire resurgir ces isoglosses sous-jacentes ${ }^{20}$ de la géolinguistique dominicaine - autant interlinguistique qu'intralinguistique - ainsi que leurs rapports identitaires dans leurs aires d'extension respectives afin de mieux saisir l'identité linguistique dominicaine. En effet, le but est d'essayer de rendre visibles les autres isoglosses ${ }^{21}$ pour que l'on puisse mettre en lumière le caractère protéiforme de l'identité dominicaine alors qu'elle est perçue comme un trait monolithique. Cela constitue un artefact politique qui sert à endiguer l'interculturalité.

Pour ce faire, on aura recours aux recherches réalisées notamment sur le terrain par certains socio(ethno)linguistes - notamment Luis A. Ortiz López (2015), Rosas Mayén Norma (2014), Juan R. Valdez (2010) et William W. Megenney (1990a) - pour essayer de (r)établir - à partir de leur(s) trait(s) phonétiques le(s) plus caractéristique(s) ${ }^{22}$ - les différentes isoglosses sous-jacentes non cartographiées ${ }^{23}$ dans la carte dialectologique dominicaine.

10 L'intérêt de ces travaux est de montrer comment sont les Dominicains ${ }^{24}$ par le biais de leurs identités linguistiques. On doit donc, suivant les indications d'Alvar, «abarcar todos los niveles donde existe diferenciación geográfica $»^{25}$ pour déceler au mieux ces identités.

\section{Isoglosses intralinguistiques}

11 En tenant compte du contexte général panhispanique et du fait aussi qu'elle fait partie $\mathrm{du}$ diasystème/suprasystème de la langue espagnole ${ }^{26}$, la variante linguistique dominicaine est prise comme une modalité homogène ${ }^{27}$. Cependant ce n'est pas le cas, bien au contraire. La géographie linguistique dominicaine est bien plus complexe que ce que nous pouvions imaginer. Elle ne se limite même pas à ses démarcations géographiques : sa complexité, en fait, va au-delà comme nous pourrons constater par la suite.

12 La République Dominicaine est généralement divisée en trois grandes régions: la région Nord ou Cibao, la région Sud-ouest et la région Sud-est. Voir la carte ci-dessous. 


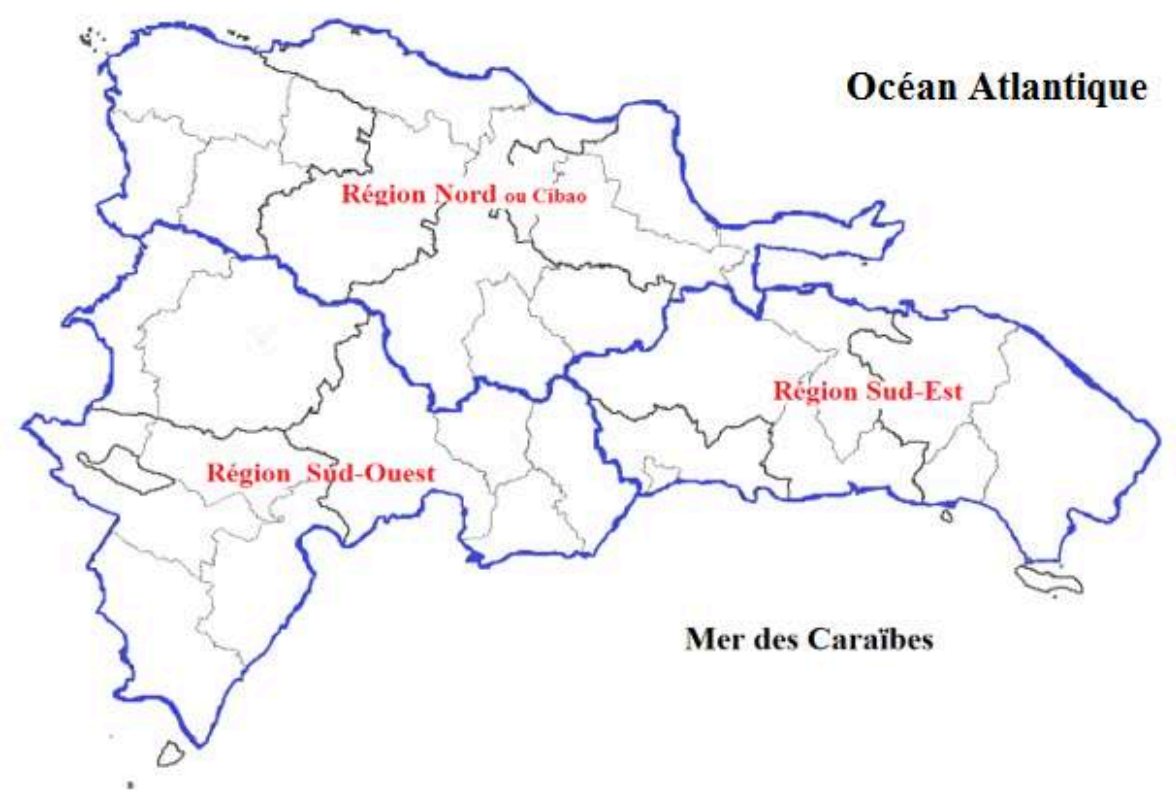

Chacune de ces régions est notamment caractérisée par un ou plusieurs phénomènes phonétiques concrets ${ }^{29}$. Ainsi la Région du Sud-ouest est caractérisée par les phénomènes de latéralisation de la rhotique percussive $/ \delta />[1]$ et par celui du rhotacisme de la latérale / $/ />[\Gamma]$ dans certaines provinces. La région Sud-est, à son tour, manifeste une gémination des rhotiques percussives selon Carlisle González Tapia: «La característica lingüística general que siempre se ha señalado como tipificadora de esta región ha sido el fenómeno de la geminación $»^{30}$. En revanche, la Région Nord ou Cibao se caractérise par le phénomène de la semi-vocalisation de la percussive et la consonne latérale ${ }^{31}$. Le schéma proposé par Toribio ${ }^{32}$ montre assez bien, de manière générale, ces variations diatopiques ${ }^{33}$ :

Norm : [faltár], [fáltas], [faltáßãn]

Santo Domingo ${ }^{34}$ : [faltál], [fálta], [faltáßãn], [faltáßã]

Cibao Valley: [fajtáj], [fájta], [fajtáßãn], [faitáßã]

Southern coast : [fartár] ,[fárta], [fartáßãn], [fartáßã]

Canfield ${ }^{35}$ envisage une catégorie additionnelle dans laquelle on pourrait englober les enclaves afro-hispaniques comme Villa Mella et «algunas regiones del interior ${ }^{36}$. Et pour être plus précis : La capital, Samaná, la zone frontalière et les bateyes ${ }^{37}$ pourraient être inclus dans cette catégorie additionnelle qui constitue les isoglosses sous-jacentes. Voyons cas par cas les identités linguistiques de ces zones, tout d'abord, les isoglosses principales et puis celles qui sont ou demeurent sous-jacentes ${ }^{38}$.

\section{Région Nord ou Cibao}

Le phénomène de la vocalisation de la rhotique percussive est le trait phonétique le plus caractéristique des habitants de cette région: "Dentro del territorio de la República Dominicana, entre los rasgos fonéticos que más distintamente caracterizan a la región del Cibao, ocupa lugar de privilegio la llamada vocalización de las líquidas [...] en posnuclear en la sílaba ${ }^{39}$. C'est donc un phénomène endogène et même répandu 
dans toutes les provinces de cette région : «El Cibao es la única región que aparece ofrecer una presencia general de su fenómeno característico (la semivocalización) en todas las provincias [...] » ${ }^{40}$. Sa fréquence de réalisation chez les locuteurs est corrélée à leur statut social. Ainsi plus les locuteurs se situent en dessous du spectre du sociolecte, plus ils réaliseront de vocalisations ${ }^{41}:$ «En el estrato social bajo [...] mayormente entre campesinos de todas las edades y de ambos sexos ${ }^{42}$. C'est dans ce spectre social qu'est réalisée le plus souvent cette vocalisation.

16 L'origine de ce phénomène est attribuée à la prononciation des immigrants qui venaient des Îles Canaries pendant la colonisation. Ils se sont établis dans cette région au début du $\mathrm{XVIII}^{\mathrm{e}}$ afin de créer un mur humain destiné à empêcher la fréquentation - et protéger l'identité collective - de cette zone par les pirates et corsaires français ; ce mur protégeait aussi des futures incursions haïtiennes ${ }^{43}$. Golibart signale que ce phénomène est proprement d'origine canarienne car il a également existé à Porto Rico jusqu'au milieu du $\mathrm{XIX}^{\mathrm{e}}$ siècle ${ }^{44}$. Pour lui, il est très significatif que ce trait phonétique existe - ou ait existé - dans trois endroits où la présence canarienne est attestée : Porto Rico, la Région Nord de la République Dominicaine et St. Bernard Parish (Louisiane, aux États-Unis). Pour étayer son hypothèse, il prend en compte aussi l'étrange vocalisation de la dentale du groupe consonantique $/ \mathrm{dr} />$ [i], qui se produit encore aux Îles Canaries. Par exemple padre > [payre]. Ce genre de vocalisation existe aussi à St. Bernard Parish ${ }^{45}$. Ce phénomène phonétique se trouve aussi à Porto Rico, mais on n'en a le témoignage que dans la poésie rurale de ce pays $^{46}$. Il se peut que ce phénomène se retrouve ailleurs: "Aunque el área focal de este fenómeno se halla en el Cibao, el mismo se encuentra en el habla de habitantes de otras zonas como por ejemplo, en las áreas rurales de la provincia del Seybo $»^{47}$. Mais pour les Dominicains, ce trait phonétique est étroitement lié au Cibao: "De todos modos, para los dominicanos el rasgo está tan asociado al Cibao que se le puede llamar legítimamente Vocalización Cibaeña $»^{48}$.

17 Un autre phénomène linguistique - mais cette fois-ci du type morphosyntaxique donne une physionomie spéciale à la sous-variante cibaeña: c'est l'usage du pronom neutre ello comme pronom personnel sujet : « Este rasgo fonológico [la vocalisation] -y también el uso del pronombre impersonal ello- deja aparecer el español cibaeño como la variedad diatópica más destacada en el Caribe insular hispánico $»^{49}$.

En raison de ces phénomènes phonétiques, la sous-variante cibaeña est très stéréotypée $^{50}$. Elle se manifeste dans la littérature dominicaine ${ }^{51}$, dans la musique surtout dans le genre musical nommé perico ripiao - et dans le folklore dominicain ${ }^{52}$. Les cibaeños sont, du fait de leur façon de parler, l'objet de moqueries de la part des habitants de la capitale, y compris à la télévision. En témoigne ici une cibaeña : «El capitaleño se mofa del cibaeño hasta en las comedias por la $<\mathrm{i}>$. Cae gracioso... En la televisión te ponen un cibaeño y le ponen la $<\mathrm{i}>$, y te hace reír. [Y la $<1>$ no?] No... la $<1$ $>$ no... quizás sean los cheques de la capital $»^{53}$.

19 À partir de ce témoignage on peut faire le constat d'une situation de diglossie au sein du parler dominicain. L'accent cibaeño est renvoyé au monde rural face à celui du monde urbain, comme le constate également Orlando Alba ${ }^{54}$ :

A muchas personas en la República Dominicana les suena menos vulgar la forma puelta que otra como pueita, a pesar de que desde un punto de vista puramente lingüístico, en ambas se produce lo mismo: un cambio que transforma la /r/ en otro sonido. La versión pueita parece menos refinada y tal vez rústica, precisamente 
porque esa pronunciación se asocia con hablantes campesinos con muy escasa o sin ninguna instrucción escolar. En cambio, la primera (puelta) se relaciona con los residentes de la Capital, lo que la hace socialmente más tolerable ${ }^{55}$. enraciné chez les cibaeños et en même temps c'est la marque principale de différenciation identitaire entre les capitaleños et les cibaeños. Cette identité linguistique dépasse même les frontières dominicaines, comme le souligne Toribio ${ }^{57}$ : «The difference between community vernacular and prescribed norm significantly impacts Dominicans in the US. Especially vulnerable are children and adolescents, who are exposed to Dominican Spanish at home and acquire stigmatized forms that often become the basis for teachers' negative impressions ». Le témoignage suivant corrobore son argumentation :

Yo conozco muchachos, que han nacido allá en Estados Unidos, que nunca conocían la República Dominicana y hablaban con una $<\mathrm{i}>$ más fuerte que cualquier gente de un campo de aquí. Ese caso lo vi yo en un muchacho que nació en Lawrence, Massachusetts. Y tú lo oías hablando y tú creías que estaba hablando con un muchacho de cualquier campo de Salcedo, porque los papás eso era lo que hablaban. Y ellos estudiando español en la escuela y estudiando inglés, y hablaban común y corriente como cualquier cibaeño, cibaeños de los que hablan mal ${ }^{58}$.

En prenant en compte ces propos la sociolinguiste dominicaine conclut: «language loyalty in the Dominican diaspora is a strong indicator that the Dominican dialect is an important feature of Dominican ethnic identy $»^{59}$.

D'ordinaire, ces isoglosses se trouvent à l'intérieur du pays et, du fait de la migration, à l'extérieur du pays également. Elles deviennent donc transfrontalières puisqu'il y a plus d'un million et demi de dominicains qui vivent aux Etats-Unis ${ }^{60}$ et chez eux subsistent leurs traits linguistiques identitaires ${ }^{61}$.

\section{Région Sud-ouest}

Cette zone se caractérise par la fréquente neutralisation du phonème /l/ en / $/$, surtout dans les provinces suivantes: Azua, Barahona et San Juan de la Maguana. Valdez l'attribue au sociolecte bas : «Esta modalidad fonética es más sistemática en el habla de campesinos y obreros con un nivel sociocultural bajo $»^{62}$. Ainsi les locuteurs articulent ['sarsader'pojo] au lieu de ['salsadel'pojo] ${ }^{63}$. Orlando Alba a aussi signalé ce rhotacisme chez les habitants du Sud: «[...] el cambio de la /l/ a una [r], cuando está colocada en posición final de sílaba y de palabra (farda -falda, y paper -papel), solamente se da, dentro de la zona del Caribe, en el sur de la República Dominicana ${ }^{64}$. Il précise également que :

[...] algunas de las manifestaciones de las líquidas (ere y ele) señalan una diferencia de carácter cualitativo, ya que unos hablantes producen unos sonidos que otros no pronuncian nunca o casi nunca. Por ejemplo, una persona que dice úrtimo, en vez de último, queda identificada con bastante seguridad no solamente en cuanto a su nivel social bajo o medio bajo, sino también como habitante de la región suroeste del país ${ }^{65}$. 


\section{Région Sud-est} cantar [kan'ta] et la gémination de fuerte ['fwette] ${ }^{66}$. En ce qui concerne la gémination, Carlisle González Tapia considère que ce phénomène ne se produit pas de manière homogène mais seulement dans certaines provinces :

La característica lingüística general que siempre se ha señalado como tipificadora de esta región ha sido el fenómeno de la geminación. Sin embargo, tanto para la región Sur como para esta, los fenómenos característicos no son generales a nivel diatópico, sino que se concentran más en una u otra provincia o localidad determinada ${ }^{67}$.

\section{Les isoglosses sous-jacentes}

En ce qui concerne les isoglosses sous-jacentes on peut dire qu'elles sont généralement constituées par cinq catégories additionnelles (les plus représentatives) :

1. La Capitale : La neutralisation des phonèmes $/ \delta /$ et $/ 1 /$ est considérée propre au parler dominicain. Mais c'est à Saint Domingue que le lambdacisme se produit davantage, surtout en position implosive : suerte ['swelte], placer [pla'sel] ${ }^{68}$. Ce phénomène - la latéralisation de la percussive $\mathrm{e}^{69}$ - est pris comme marque diatopique ${ }^{70}$. De manière générale, c'est la sousvariante la plus acceptée ${ }^{71}$, considérée ainsi comme la modalité standard en République Dominicaine.

2. Villa Mella: le phénomène phonétique qui caractérise l'espagnol de Villa Mella est la neutralisation $\mathrm{du} / \mathrm{d} /$ intervocalique $\mathrm{e}^{72}$. Dans cette commune on peut constater que le /d/ se réalise de deux manières différentes. Soit il s'articule comme une fricative [đ], par exemple puéde, soit il devient une vibrante simple (percussive) comme puero ${ }^{73}$.

3. Samaná : mis à part les Afro-américains affranchis qui se sont établis dans cette péninsule, il y a, apparemment, un autre groupe d'anglophones qui parlent une variété de l'anglais de l'Inde Occidentale ${ }^{74}$. L'anglais continue à être une $\mathrm{L} 2^{75}$ pour la plupart des habitants les plus âgés ${ }^{76}$. Il y a également beaucoup d'habitants qui parlent le créole haïtien ${ }^{77}$; de ce fait, les habitants bilingues espagnol-anglais possèdent des formes phonologiques un peu différentes. Il en va de même pour les habitants bilingues créolophones ${ }^{78}$. Cette zone possède un lexique qui est le produit de la créolisation des trois langues parlées sur le territoire: l'espagnol, l'anglais et le créole haïtien ${ }^{79}$. Suite à ces rencontres, Samaná s'est constitué une culture hétéroglossique où chaque communauté linguistique négocie son identité respective ${ }^{80}$. Valdez a tout à fait raison quand il dit que « sin ninguna duda, esta región es un complejo campo de identidades y hablas $»^{81}$.

4. Les autres enclaves linguistiques, représentées notamment par les bateyes ${ }^{82}$. On y trouve un espagnol hybride dans certains cas et dans la plupart des cas un bilinguisme stable manifesté principalement par la descendance issue lors des vagues successives de la migration haïtienne.

5. Zone frontalière (dont les habitants, fruit du brassage entre couple binationaux, sont nommés rayanos). Les populations qui habitent sur cette ligne configurent un espace transnational défini par des relations économiques, raciales et culturelles complexes ${ }^{83}$. Dans cette zone se manifestent un bilinguisme créole/espagnol et, de ce fait, une hybridation de l'espagnol dominicain. 


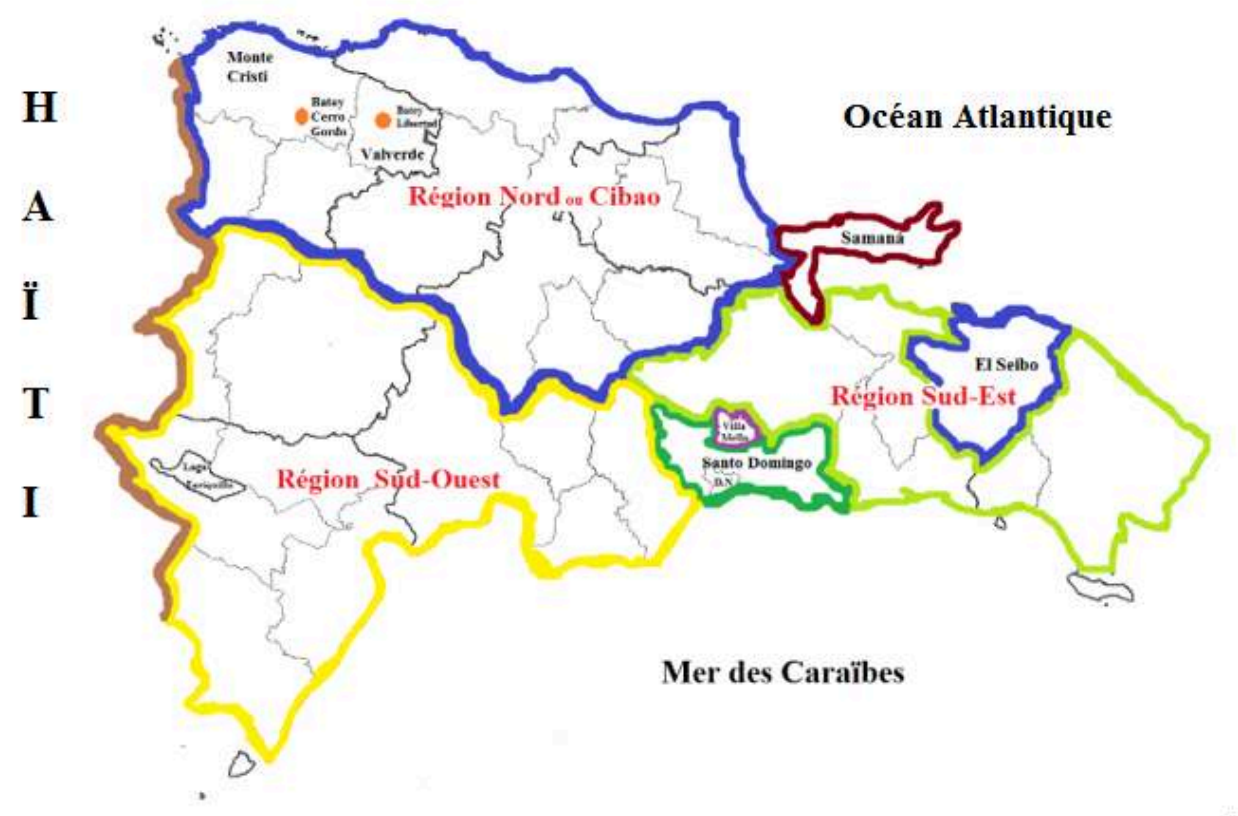

27 Sur la carte :

Isoglosses principales :
A. $/ \mathbf{l} /$ et $/ \mathbf{r} />[\mathbf{i}]$
B. $/ \mathbf{l} />[\mathbf{r}]$
C. $/ \mathbf{r} />[\varnothing]$ ou gémination.

Isoglosses sous-jacentes :

1. $/ \mathrm{f} />[1]$ (Santo Domingo)

2. $/ \mathrm{d} />[\mathrm{r}]$ (Villa Mella)

3. $/ \Gamma />[\mathrm{i}]+$ plurilinguisme $=$ créolisation du lexique espagnol (Samaná).

4. $/ \mathrm{\Gamma} />[\mathrm{l}],[\mathrm{i}],[\mathrm{R}]+$ bilinguisme $=$ interférences linguistiques (enclaves $=$ bateyes) .

$5 . / \Gamma />[1],[i],[R]+$ bilinguisme $=$ interférences linguistiques (zone frontalière) .

\section{Isoglosses interlinguistiques}

Quant aux langues qui cohabitent sur le territoire dominicain, leurs frontières linguistiques sont toujours difficiles à tracer et elles ne correspondent pas aux frontières politiques. Évidemment, comme le dit Calvet, « [...] frontières linguistiques et frontières politiques ne correspondent pas $^{85}$ ", "et les choses sont parfois très complexes $\|^{86}$. C'est tout à fait le cas en République Dominicaine où se croisent plusieurs frontières linguistiques parmi lesquelles l'espagnol, le créole haïtien et l'anglais. 


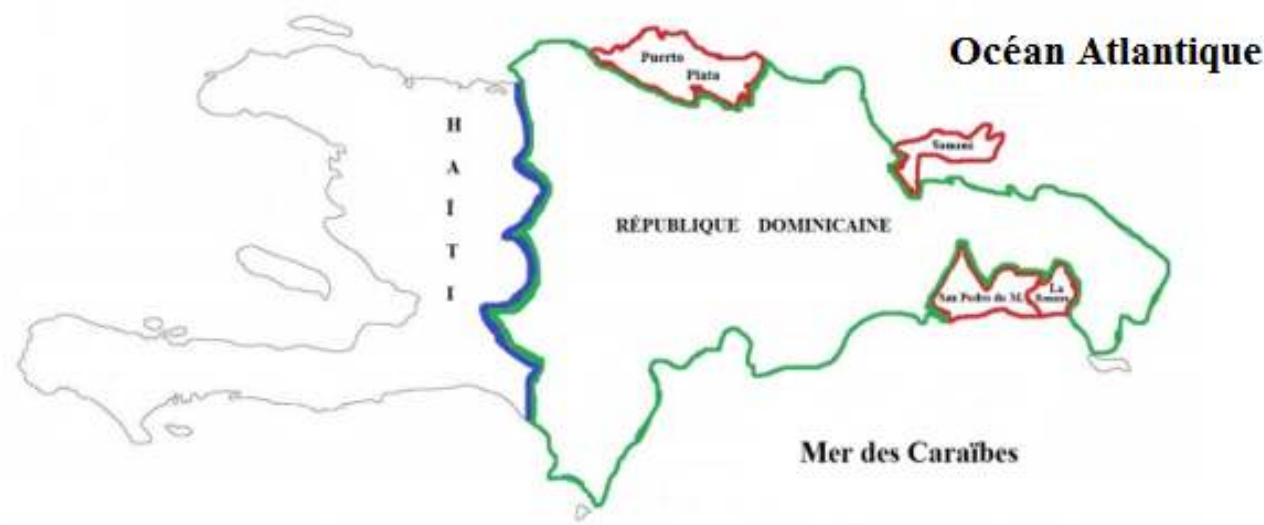

Sur la carte :

- Anglophone : San Pedro, La Romana (Sud-est), Samaná et Puerto Plata (Nord).

- Créolophone : les nombreux bateyes dispersés, la frontière et certains quartiers de Samaná.

- Hispanophone.

Le créole haïtien est parlé tout le long de la frontière - ou la raya - et dans tous les bateyes éparpillés dans toute la géographie dominicaine ainsi que dans ses villes principales.

Une partie de ses locuteurs est bilingue, notamment, la nouvelle génération issue des différentes vagues migratoires ${ }^{88}$. De nos jours, le batey est devenu un espace socioculturel où se maintiennent et se consolident non seulement les valeurs et manifestations de la culture haïtienne, mais également la langue - le créole haïtien -, la religion - le vaudou - comme symboles identitaires ${ }^{89}$. En revanche, pour l'anglais, ses locuteurs se concentrent autour de trois villes Samaná, San Pedro de Macorís et dans une moindre mesure Puerto Plata. Cette communauté linguistique et culturelle diminue de plus en plus puisque les nouvelles générations n'acquièrent pas cette langue comme L1 (langue première) ni L2 (langue secondaire).

Dans le cas de la ville de Samaná, il y a « un conjunto de fenómenos sociopolíticos [que le] da [...] un marco histórico diferente al resto del país y unas características peculiares que se recogen al primer contacto $"^{90}$. À Samaná cohabitèrent et cohabitent encore trois sources linguistiques bien définies ${ }^{91}$ :

1. L'anglais, situé au Nord-ouest de la ville.

2. Le patois ${ }^{92}$, situé au Sud-ouest de la ville.

3. Et l'espagnol, dont le noyau principal se trouve dans le secteur Los Cacaos.

33 Le plan ci-dessous, réalisé par Carlisle González Tapia (1985, p. 125), illustre assez bien cette distribution diatopique dans la ville de Samaná. 


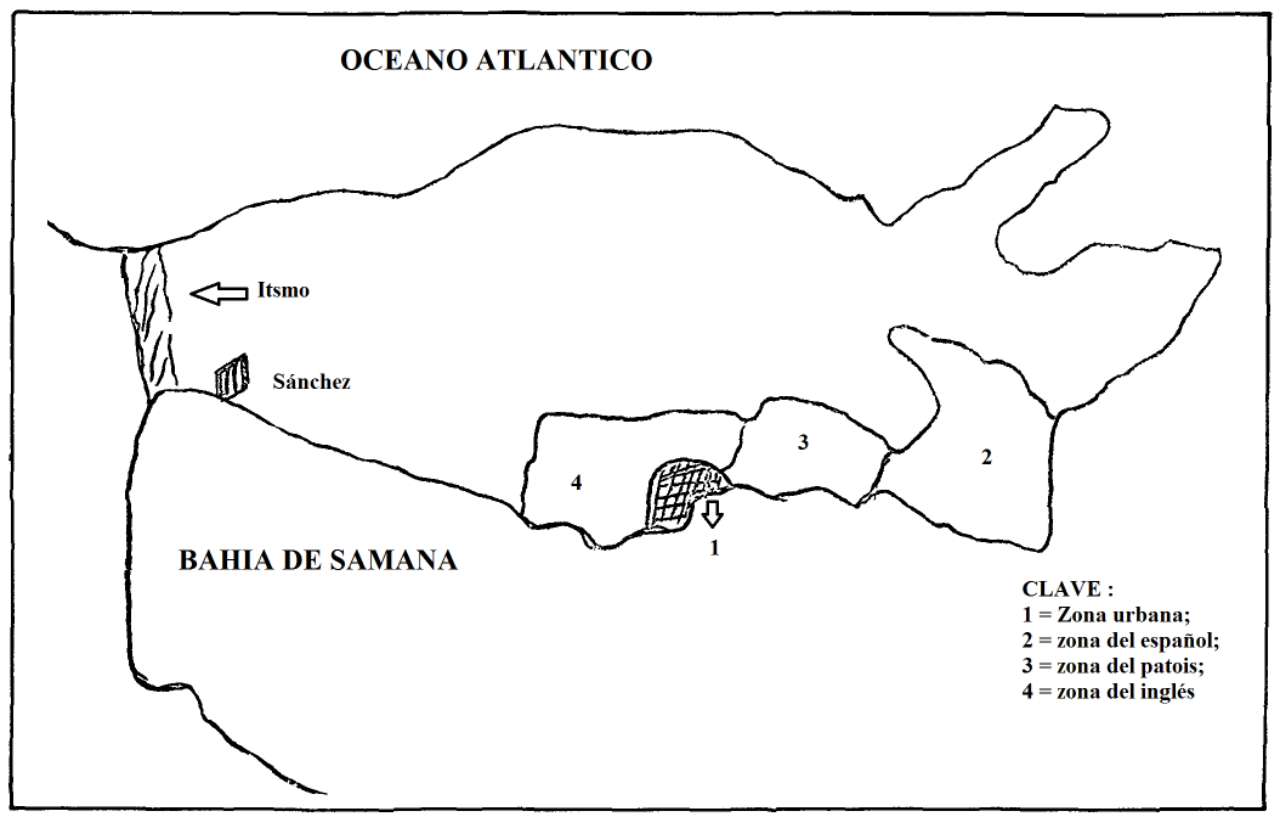
1. Zone urbaine.
2. Zone des hispanophones.
3. Zone des créolophones.
4. Zone des anglophones.

Dans le contexte glossopolitique national, ces espaces linguistiques sont renvoyés au monolinguisme, car ce plurilinguisme demeure presque ignorép3. Par contre, la communauté créolophone est une communauté très active. C'est la première langue minoritaire qui représente autour de $10 \%$ de la population ${ }^{94}$. Elle a créé de multiples espaces de pratiques langagières sur tout le territoire national. Au contraire, la communauté anglophone est caractérisée par son caractère d'endogamie grégaire et sédentaire, créant ainsi son enclave linguistique principale à Samaná.

Or, malgré ce foisonnement plurilinguistique, pour certains historiens, l'espagnol dominicain est aussi l'une des marques identitaires : « los dos símbolos que han tenido mayor significación para diferenciar el pueblo haitiano y el pueblo dominicano ha sido el color de la piel y el lenguaje. En posiciones menos relevantes se citan también la religión y las costumbres $»^{95}$. Mais la question linguistique s'est superposée à la question raciale étant donné que le peuple dominicain est un peuple bien métissé ${ }^{96}$. De nos jours, le seul symbole tangible de différenciation ethnique et sociale a été et est encore la langue. Cet axiome s'est matérialisé physiquement avec les deux traités frontaliers ${ }^{97}$ entre Haïti et la République Dominicaine et également sur le plan social par rapport à la population créolophone à l'intérieur du pays. Ainsi, c'est une double barrière externe/interne qui a été utilisée «[...] como línea épica de afirmación (nacional) impulsada por la intelectualidad nacionalista que accionaba desde movimientos culturales [...] $\gg^{98}$. Si les habitants du Nord sont stéréotypés du fait de leur vocalisation de la rhotique percussive, à leur tour, les habitants créolophones sont stigmatisés ${ }^{99}$ à cause de leur(s) langue(s).

En outre, le récit d'une Histoire conflictuelle et la conscience raciale entre ces deux États accentue cette divergence. Par ailleurs, le discours de la classe dominante 
dominicaine ${ }^{100}$ a renforcé ce sentiment qui se répercute péjorativement sur les habitants autochtones créolophones : «En la República Dominicana se habla una sola lengua : la lengua española. Y ésta es la primera y básica diferencia entre el negro dominicano y el negro haitiano» ${ }^{101}$. L'amalgame entre langue et dominicanidad a son origine dans le discours idéologique porté par la classe intellectuelle nationale, comme l'exprime Orlando Alba :

Los investigadores suelen buscar con afán únicamente los rasgos privativos o exclusivos del país en los diferentes aspectos de la realidad dominicana. Su concepción de la noción de identidad parece apoyarse en el concepto de lo distinto, del propio carácter de exclusividad, es decir, de lo ausente en el resto del mundo ${ }^{102}$.

Lipski rejoint les propos d'Orlando Alba, lorsqu'il affirme aussi que «La evolución lingüística de la República Dominicana está ligada a la historia de Santo Domingo [...] $\aleph^{103}$. Tous les éléments culturels et idéologiques s'entremêlent pour ériger l'espagnol dominicain en seul symbole sacralisé de l'identité dominicaine, la dominicanidad.

\section{Conclusions}

À travers une idéologie monoglossique et monoculturelle, la société dominicaine prétend ignorer son réel passé historique et son actuel présent plurilinguistique. Ces diacritiques sont les piliers identitaires de la nation quisqueyana. Cette idée de s'attacher à un seul et unique substrat culturel correspond bien à celle que dénonce Charaudeau : "L'idée qui veut que l'individu ou un groupe humain fonde son existence sur une pérennité, sur un substrat culturel stable qui serait le même depuis l'origine des temps, sur une "essence " ne peut tenir " ${ }^{104}$. Cette démarche monogénétique a servi à créer des barrières physiques, des murs mentaux - dans certaines périodes historiques ils furent infranchissables - entre les différentes enclaves ou espaces linguistiques afin de promouvoir le rejet de certains héritages culturels. Pourtant, les différentes études linguistiques ont démontré l'existence d'un éventail d'identités linguistiques liées intrinsèquement à la culture dominicaine et à son Histoire.

Par le biais de ces pratiques linguistiques se manifeste «l'hétérogénéité fondatrice et constitutive des identités imaginées des Amériques/Caraïbes ${ }^{105}$ qui est toujours présente - en l'occurrence - dans le patrimoine culturel. C'est pourquoi la dominicanidad doit devenir synonyme de multiculturalité active et modèle pour toutes les pratiques langagières des Caraïbes ${ }^{106}$. La multiculturalité est un paradigme pragmatique de ce laboratoire linguistique que l'on appelle la Caraïbe.

Ces isoglosses intralinguistiques et interlinguistiques - y compris les sous-jacentes - sont l'exemple tangible de la complexité historique, linguistique, identitaire, culturelle, ethnique et politique de l'actuelle République Dominicaine et bien entendu de son passé colonial qui la hante - plus que jamais ${ }^{107}$ - encore. Ces barrières - soit physiques soit mentales - n'ont pas de raison d'être dans une nation qui est le fruit du métissage. 


\section{BIBLIOGRAPHIE}

Orlando ALBA, «A propósito de la identidad lingüística dominicana », Santiago: Eme-Eme Estudios Dominicanos, vol. XII, nº 72, (mayo-junio 1984), p. 31-45<URL : https://dloc.com/

PUCMMA0011/00074/33j>.

Orlando ALBA, Variación fonética y diversidad social en el español dominicano de Santiago, Santiago, Pontificia Universidad Católica Madre y Maestra, 1990.

Orlando ALBA, La identidad lingüística de los dominicanos, Santo Domingo, Ediciones Librería La Trinitaria, Brigham Young University, 2009.

Carmen AlÉN-GARABATO, Henri Boyer, Ksenija DJOREVID lÉONARD et Bénédicte PIVOT, « Présentation », Carmen ALÉN-GARABATO, Henri BOYER, Ksenija DJOREVID LÉONARD et Bénédicte PIVOT (dir.), Identités, conflits et interventions Sociolinguistiques, Limoges, Lambert-Lucas, 2018. p. 7-21.

Juan ANTONIO ALIX, « Un Campesino dominicano que estuvo en Haití vendiendo unos andullos y a su regreso tuvo una entrevista muy curiosa », Décimas / Juan Antonio Alix; prólogo: José R. López, Santo Domingo, Imprenta de J. R. Vda. García, 1927.

Carlos ANDÚJAR PERSINAL, La cultura y la sociedad dominicana una mirada socioantropológica, Santo Domingo, Instituto Tecnológico de Santo Domingo (INTEC), 2019.

Manuel ALVAR, Estructuralismo, geografía lingüística y dialectología actual, Madrid, Editorial Gredos, S. A., 1969.

Manuel ALVAR, El español en la República Dominicana. Estudios, encuestas, textos, Alcalá de Henares, Universidad de Alcalá. Servicios de Publicaciones, La Goleta Ediciones, 2000.

Carlos ANDÚJAR PERSINAL, « La identidad dominicana y sus fantasmas », Ciencia y Sociedad, Volumen XXIII, $n^{\circ} 4$, octubre-diciembre (1998), p. 484-491.

José Luis BLAS ARROYO, Sociolingüística del español. Desarrollo y perspectivas en el estudio de la lengua española en contexto social, Madrid, Ediciones Cátedra (Grupo Anaya, S.A), 2005, 2012.

Henri BOYER, «Idéologie sociolinguistique et politiques linguistiques (intérieures) de la France », Synergies. Pays germanophones, $\mathrm{n}^{\circ} 5$ (2012), p. 93-105.

Jean-Louis CALVET, « Langues, minor(is)ations, marginalisations : une image de la linguistique ? » Lidil [En ligne], 44 | 2011, (mis en ligne le 15 juin 2013) [consulté le 9 mars 2021] <URL : http://journals.openedition.org/lidil/3149> ; DOI : https://doi.org/10.4000/lidil.3149.

Louis-Jean CALVET, « Des frontières et des langues ». Entretien avec Thierry Paquot, Marseille ", Hermès, La Revue, n 63, CNRS Éditions, (2012/2), p. 51-56 < URL : https:// www.cairn.info/revue-hermes-la-revue-2012-2-page-51.htm>.

Maite CELADA et Xoán LAGARES, « República Dominicana/Haití - Fronteras lingüísticas y políticas en el territorio de la Hispaniola. Entrevista a Juan VALDEZ », Abehache, año 2, n 2 ( $1^{\text {er }}$ semestre 2012), p. 167-173.

Patrick CHARAUDEAU, «Identité linguistique, identité culturelle : Une relation paradoxale », Christian Lagarde (éd.), Le discours sur les « langues d'Espagne »1978-2008, Perpignan, Presses Universitaires de Perpignan, 2009, p. 21-39. 
Peter Cichon et Max Doppelbauer, « Prefacio », in Peter Cichon et Max Doppelbauer (eds.), La España multilingüe, Viena, Praesens Verlag, 2008, p. 7-11.

Carlos DOBAL, « Hispanidad y Dominicanidad », Santiago, Eme-Eme Estudios Dominicanos, vol. XII no 72, (mayo/junio, 1984), p. 89-99 <URL : https://dloc.com/PUCMMA0011/00074/91j>.

Pierre ENCREVÉ, « Présentation », dans William Labov, Sociolinguistique, Paris, pour la traduction by Les éditions de Minuit, 1976, p. 9-35.

Ana fÉLIZ LAFONTAINE, « La Identidad Cultural Dominicana: Más allá de los discursos esencialistas », Perspectivas, ํㅡㅇ 05-17, (2017), p. 1-10.

Pablo GOLIBART, « Orígenes de la vocalización en el habla cibaeña », Eme Eme: Estudios Dominicanos, 4(22), Santiago, Universidad Católica Madre y Maestra (UCMM), (1976), p. 127-144 < URL : https:// dloc.com/PUCMMA0011/00040/5j>.

María Filomena GONZÁLEZ y Rubén SILIÉ, « La nación dominicana en la enseñanza de la historia a nivel primario », vol. XIV nº 14 (79), Santiago, Eme-Eme Estudios Dominicanos, (julio-agosto, 1985), p. 17-30< URL : https://dloc.com/PUCMMA0011/00081/17j>.

Carlisle GONZÁLEZ TAPIA et Benavides CELSO, « ¿Existen rasgos criollos en el habla de Samaná? », Orlando Alba (ed.), El español del Caribe. Ponencias del VI Simposio de Dialectología, Santiago de los Caballeros, 1981, p. 105-132.

Carlisle GONZÁLEZ TAPIA, « El español dominicano, un estudio diatópico de "R" y "L"», Anuario de Lingüística Hispánica, vol. 6, (1990), p. 225-254.

Carlisle GONZÁLEZ TAPIA, Estudio sobre el habla culta dominicana (resultados parciales de una investigación). Con un estudio especial de los idiolectos de Bosch y Balaguer, Santo Domingo, Editora universitaria - UASD, 1994.

Eva GUGENBERGER, «El castellano y las lenguas regionales en España: Bilingüismo e hibridación », Cichon, P., Doppelbauer, M., (eds.), La España multilingüe, Viena, Praesens Verlag, , 2008, p. 31-52.

Federico HENRÍQUEZ GRATEREAUX, « Negros de mentira y blancos de verdad », Santiago, Eme-Eme Estudios Dominicanos, vol. XV no 81, sep./dic., (1988), p. 73-80<URL : https://dloc.com/ PUCMMA0011/00083/75j>.

Pedro HENRÍQUEZ UREÑA, El español en Santo Domingo, (Instituto de Filología de la Universidad de Buenos Aires, Biblioteca de Dialectología Hispanoamericana, t.v.), Buenos Aires, Casa editora Coni, 1940.

Silke JANSEN, « Monolingüismo y bilingüismo en el discurso de la lingüística hispánica », K. Wieland, K. Süselbeck et V. Eilers (eds.), Aspectos del desarrollo de la lingüística española a través de los siglos, Hamburgo, Verlag, , 2010, p. 111-124.

Silke JANSEN, « Ethnic difference and language ideologies in popular Dominican literature: the case of Haitianized speech », International Journal of the Sociology of Language 233, (2015), p. 73-96.

Andre KLUMP, La dominicanidad de los dominicanos en RD, EE.UU. y España. Conferencia en línea, Centro de Estudios Europeos, Escuela de Humanidades y Ciencias Sociales de la Pontificia Universidad Católica Madre y Maestra (PUCMM), República Dominicana, 27 de octubre de 2020, $<$ URL : https://investigacion.pucmm.edu.do/estudios-europeos/Documents/ConferenciaPUCMM-Klump.pdf>. 
Christian LAGARDE, Identité, langue et nation. Qu'est-ce qui se joue avec les langues ?, Canet (Catalunya), Trabucaire, 2008.

Christian LAGARDE, « La condition d'étranger : une mise en discours de la conscience de soi et de la perception de l'autre » [En ligne], 10, 2013, (mis en ligne le 27 juin 2013) [consulté le 9 mars 2021] <URL : http://journals.openedition.org/ccec/4505> ; DOI : https://doi.org/10.4000/ccec.4505.

Victorien LAVOU ZOUGNBO, " Métissage et créolisation. Questionnements et contrepoint ", dans Jean-Arsène Yao (coord.), Áfricas, Américas y caribes. Representaciones colectivas cruzadas (siglos XIXXXI), Alcalá de Henares, Universidad de Alcalá de Henares publicaciones, 2020, p. 143-155.

John M. LIPSKI, El español de América, Madrid, Ediciones Cátedra (grupo Anaya, S.A.), 1996, 2014.

Antonio LlUBERES NAVARRo, « Caribe, Azúcar y Migración, 1789-1944», Santiago: Eme-Eme Estudios Dominicanos, vol. II n 39 , (noviembre-diciembre 1978), p. 3-44<URL : https://dloc.com/ PUCMMA0011/00040/5j>.

Michael MALEK, « El régimen de Ulises Heureaux : 1882-1899, desarrollo y dictadura en la República Dominicana », Eme-Eme: Estudios Dominicanos, 11(65), (1983), p. 31-60<URL : https:// dloc.com/PUCMMA0011/00040/5j>.

Frank MARINO HERNÁNDEZ, « La inmigración haitiana en la República Dominicana », Santiago: EmeEme Estudios Dominicanos, vol. I n ${ }^{\circ}$ 5, (marzo-abril 1973), p. 24-56, <URL : https://dloc.com/ PUCMMA0011/00007/25j>.

Rosas MAYÉN NORMA, « Las consonantes líquidas en el kreyñol, una variedad del español afrodominicano », Dialectología 12 (2014), p. 109-130.

Rafael Lluís NINYOLES et Henri BOYER, « Entretien avec Rafael Lluís Ninyoles. Réalisé par Henri Boyer », Carmen Alén Garabato et Romain Colonna (dirs.), Auto-odi. La « haine de soi » en sociolinguistique, Paris, L'Harmattan, 2016, p. 15-29.

Rafael A. NÚÑEZ CEDEÑo, La fonología moderna y el español de Santo Domingo, Santo Domingo, Editora Taller, 1980 .

Rafael A. NÚÑEZ CEDEÑO, « El español de Villa Mella: En desafío a las teorías fonológicas modernas », Orlando Alba (ed.), El español del Caribe. Ponencias del VI Simposio de dialectología, Santiago de los caballeros, Universidad Católica madre y Maestra, (1982), p. 221-236.

Luis A. ORTIZ LÓPEZ, « Transnacionalidad e identidades lingüísticas en la frontera dominicohaitiana », International Journal of the Sociology of language, $n^{\circ} 233,(2015)$, p. 15-39.

Emilio RODRíGUEZ DEMORIZI, Lengua y folklore de Santo Domingo. Santiago, República Dominicana, Primera Edición Universidad Católica Madre y Maestra, 1975.

Nelson ROJAS, « Sobre la semivocalización de las líquidas en el español cibaeño », Orlando Alba (ed.), El español del Caribe. Ponencias del VI Simposio de dialectología, Santiago de los caballeros, Universidad Católica madre y Maestra, 1982, p. 271-287.

Mercedes ROMÁN FERNÁNDEZ, El español dominicano en el siglo XVIII. Análisis lingüístico de la historia de la conquista de la isla Española de Sto. Domingo de L. J. Peguero, Anejo n. IX de la Revista Cuadernos de Filología, Valencia, 1994.

Ariel Osvaldo TAPIA MEDINA, « Hacia una nueva conciencia sociolingüística: afrodominicanismo y el habla dominicana ", dans Jean-Arsène Yao (coord.), Áfricas, Américas y caribes. Representaciones colectivas cruzadas [siglos XIX-XXI], Alcalá de Henares, Universidad de Alcalá de Henares publicaciones, 2020, p. 319-325. 
Ariel Osvaldo TAPIA MEDINA, « Unilinguisme vs plurilinguisme : le cas de la République Dominicaine ", Amerika [online], $\mathrm{n}^{\circ} 20$ (2020), (online since 20 July 2020) [consulté le 9 mars 2021] <URL : http://journals.openedition.org/amerika/12196> ; DOI : https://doi.org/10.4000/amerika. 12196.

Almeida Jacqueline TORIBIO, « Language variation and the linguistic enactment of identity among Dominicans », Linguistics 38-5 (2000a), p. 1133-1159.

Almeida Jacqueline TORIBIO, « Nosotros somos dominicanos: Language and Self-Definition among Dominicans ", Ana Roca (ed.), Research on Spanish in the U.S., Somerville, MA : Cascadilla Press, (2000b), p. 252-270.

Juan R. VALDEZ, « La regimentación lingüística en un escenario transnacional La República Dominicana / Haití », Language Problems and Language Planning, vol. 38:2, (2014), p. 149-166.

Juan R. VALDEZ, « Samaná (República Dominicana): ¿Baluarte del criollismo caribeño o cambio de contacto lingüístico cultural? », Estudios 18:35, Samaná (República Dominicana) (Enero Julio 2010), p. 29-48.

\section{NOTES}

1. Selon Lagarde, l'on pourrait ajouter aussi d'autres critères socioculturels comme « la race ou l'ethnie qui sont choisis pour construire une nation. Ils ont nommé les fameux "diacritiques" " (Christian LAGARDE, Identité, langue et nation. Qu'est-ce qui se joue avec les langues? Canet (Catalunya), Trabucaire, 2008, p. 87). Ces diacritique servent pour établir des traits identitaires stéréotypés d'une nation quiconque.

2. Celle que nous apprenons notamment à l'école, c'est-à-dire celle des manuels scolaires dominicains.

3. Andre KLUMP, La dominicanidad de los dominicanos en RD, EE.UU. y España. Conferencia en línea, Centro de Estudios Europeos, Escuela de Humanidades y Ciencias Sociales de la Pontificia Universidad Católica Madre y Maestra (PUCMM), República Dominicana, 27 de octubre de 2020, p. 10 ; <URL : https://investigacion.pucmm.edu.do/estudios-europeos/Documents/ConferenciaPUCMM-Klump.pdf>.

4. C'est une pratique très généralisée aux Caraïbes hispaniques, comme l'indique l'énoncé suivant : « [...] en el Caribe contemporáneo y en sociedades latinoamericanas, desde México hasta Buenos Aires, se han intentado construir las identidades nacionales a partir de la lengua, la raza, las etnias y los lazos transnacionales, pero privilegiando una lengua, el español, y a ciertos grupos o prácticas culturales, blancos y europeos, frente a otros que han quedado al margen, como han sido los africanos y sus descendientes negros [...]» (Anani DZIDZIENYO et Suzanne OBOLER, Neither Enemies Nor Friends: Latinos, Blacks, Afro-Latinos, Palgrave Macmillan, 2005 ; cité dans Luis A. ORTIZ LÓPEZ, “Transnacionalidad e identidades lingüísticas en la frontera dominicohaitiana", International Journal of the Sociology of language, $n^{\circ} 233,(2015)$, p. 27). Evidemment, la langue fait partie de cette construction parce que «l'identité linguistique est sans aucun doute la manifestation la plus tangible de l'identité culturelle " (Christian LAGARDE, Identité, langue et nation. Qu'est-ce qui se joue avec les langues ? Canet (Catalunya), Trabucaire, 2008, p. 59).

5. Luis A. ORTIZ LÓPEZ, «Transnacionalidad e identidades lingüísticas en la frontera dominicohaitiana», International Journal of the Sociology of language, $n^{\circ} 233$ (2015), p. 27.

6. Louis-Jean CALVET, "Des frontières et des langues». Entretien avec Thierry Paquot, Marseille ", Hermès, La Revue, $n^{\circ}$ 63, C.N.R.S Éditions, (2012/2), p. $5<$ URL : https://www.cairn.info/ revue-hermes-la-revue-2012-2-page-51.htm>. 
7. C'est la façon la plus efficace pour constituer une identité : « No en vano, la lengua desempeña un papel -a menudo el más importante- en la configuración de los sentimientos de pertenencia a un grupo étnico nacional» (José Luis BLAS ARROYO, Sociolingüística del español. Desarrollo y perspectivas en el estudio de la lengua española en contexto social, Madrid, Ediciones Cátedra (Grupo Anaya, S.A), 2005, 2012).

8. Henri Boyer propose plutôt le terme auto-dénigrement au lieu d'autoodi, car ce dernier ne lui parait pas une bonne interprétation de la notion d'insécurité linguistique. Voir l'entretien avec Rafael Lluís Ninyoles réalisé par lui-même en 2016, publié dans l'ouvrage : Rafael Lluís NINYoLEs et Henri BOYER, « Entretien avec Rafael Lluís Ninyoles. Réalisé par Henri Boyer », Auto-odi. La « haine de soi » en sociolinguistique, Carmen Alén-Garabato et Romain Colonna (dir.), Paris, L'Harmattan, (2016), p. 15-29. Voir également Christian LAGARDE, «La condition d'étranger: une mise en discours de la conscience de soi et de la perception de l'autre » [En ligne], 10 | 2013, mis en ligne le 27 juin (2013), p. 7, [consulté le 9 mars 2021] < URL: http://journals.openedition.org/ccec/ 4505> ; DOI : https://doi.org/10.4000/ccec.4505.

9. Celle qui a été esclavagée par les colons espagnols et français pendant l'époque coloniale.

10. La première a été contre Haïti (1844) où la question raciale et religieuse a acquis une dimension significative au niveau de traits ethniques de la nouvelle nation. La deuxième contre l'Espagne (1865) - Guerre de Restauration - où la question linguistique comme marque diatopique et idiosyncrasique a pris le devant en tant que trait définitoire de la nation dominicaine.

11. Même si «la contribución africana a la cultura dominicana constituye el influjo extrahispánico más significativo » (John M. LIPSKI, El español de América, Madrid, Ediciones Cátedra (grupo Anaya, S.A.), 1996, 2014), cette contribution demeure reniée.

12. Victorien LAVOU ZOUGNBO, «Métissage et créolisation. Questionnements et contrepoint », dans Jean-Arsène Yao (coord.), Áfricas, Américas y caribes. Representaciones colectivas cruzadas [siglos XIXXXI], Alcalá de Henares, Universidad de Alcalá de Henares publicaciones, (2020), p. 143.

13. Carlos ANDÚJAR PERSINAL, «La Identidad Dominicana y sus Fantasmas», Ciencia y Sociedad, Volumen XXIII, Número 4 octubre-diciembre 1998, p. 484.

14. Carmen ALÉN-GARABATO, Henri BOYER, Ksenija DJORDJEVID LÉONARD et Bénédicte PIVOT, "Présentation », Identités, conflits et interventions Sociolinguistiques (sous la direction de Carmen ALÉN-GARABATO, Henri BOYER, Ksenija DJORDJEVID LÉONARD et Bénédicte PIVOT), Limoges, Lambert-Lucas, 2018, p. 7.

15. Traduction: «Alors que l'identité dominicaine et la reconnaissance de soi sont directement liées à la langue espagnole, à la culture hispanique et au catholicisme, Haït est considérée comme l'antipode culturel de ce modèle; dont la langue, la culture, et la religion sont dérivées non pas des modèles européens mais des modèles africains » (Silke JANSEN, « Ethnic difference and language ideologies in popular Dominican literature: the case of Haitianized speech ", International Journal of the Sociology of Language, 233 (2015), p. 79-80).

16. Traduction: «En soulignant cette différenciation linguistique et culturelle, les idéologies linguistiques sont un moyen de tracer des frontières entre les langues ou les variétés linguistiques et de les présenter, comme symboles, intrinsèquement différentes afin de justifier la différence de chaque culture. C'est pourquoi celles-ci peuvent servir d'outil puissant de construction identitaire à travers l'“othering" " (Id.). C'est le principe d'alteridad (Patrick CHARAUDEAU, «Identité linguistique, identité culturelle: Une relation paradoxale », Christian Lagarde (Éd.), Le discours sur les «langues d'Espagne» 1978-2008, Perpignan, Presses Universitaires de Perpignan, 2009. p. 27) qui découle de l'identité imaginaire ou imaginée, laquelle «es el reconocimiento de la multilateralidad de nuestro ser cultural, pero también es el principio de la alteridad» (Carlos ANDÚJAR PERSINAL, «La Identidad Dominicana y sus Fantasmas», Ciencia y Sociedad, Volumen XXIII, Número 4 octubre-diciembre, (1998), p. 485). Pour Patrick Charaudeau, 
ce principe constitue «la preuve de notre identité lequel déclenche un double mouvement : d'attirance et de rejet vis-à-vis de l'autre » (Op. cit.).

17. Peter CICHON et Max DOPPELBAUER, «Prefacio», in Cichon, P., Doppelbauer, M., (eds.), La España multilingüe, Viena: Praesens Verlag, 2008, p. 7.

18. Carlos ANDÚJAR PERSINAL, «La Identidad Dominicana y sus Fantasmas» Ciencia y Sociedad, Volumen XXIII, Número 4 octubre-diciembre (1998), p. 484.

19. Consulter: Ariel Osvaldo TAPIA MEDINA, «Unilinguisme vs plurilinguisme: le cas de la République Dominicaine ", Amerika [online], n 20 (2020), (online since 20 July 2020) [consulté le 9 mars 2021] <URL : http://journals.openedition.org/amerika/12196> ; DOI : https://doi.org/ 10.4000/amerika.12196.

20. Pour autant elles sont bien utilisées dans les pratiques langagières d'une grande partie des locuteurs dominicains.

21. Et essayer aussi de les repérer sur la carte géographique.

22. Il y a d'autres traits linguistiques qui révèlent les caractéristiques identitaires et diatopiques de ces sous-variantes du parler dominicain - tels que les traits prosodiques et lexicaux - mais pour simplifier le travail on ne prendra en compte que les traits phonétiques issus de certains phénomènes.

23. En fait, celles qui se trouvent camouflées par les isoglosses principales, c'est-à-dire celles qui ne coïncident pas avec les frontières politiques/géographiques.

24. Carlisle González Tapia met en exergue les différences diatopiques du parler dominicain à partir de traits phonétiques pour assigner une identité linguistique à chacune des régions dominicaines (Carlisle GONZÁLEZ TAPIA, Estudio sobre el habla culta dominicana (resultados parciales de una investigación). Con un estudio especial de los idiolectos de Bosch y Balaguer, Santo Domingo, Editora universitaria - UASD, 1994, p. 13).

25. Manuel ALVAR, Estructuralismo, geografía lingüística y dialectología actual, Madrid, Editorial Gredos, S. A., 1969, p. 59.

26. Dans le discours épilinguistique des Dominicains, on établit la dichotomie suivante : castillan (variante locale) et espagnol (suprasystème général) (Manuel ALVAR, El español en la República Dominicana. Estudios, encuestas, textos, Alcalá de Henares, Universidad de Alcalá. Servicios de Publicaciones, La Goleta Ediciones, 2000, p. 32). Selon Pierre Encrevé, «c'est justement ce système pandialectal qui permet l'unification de la communauté linguistique car il relie l'ensemble des dialectes de la langue [...]» (Pierre ENCREVÉ, «Présentation », dans William LABOV, Sociolinguistique, Paris, pour la traduction by Les éditions de Minuit, 1976, p. 32).

27. On ignore ainsi « [...] las múltiples identidades lingüísticas que aún sobreviven en este rincón del Caribe, [susceptibles de] proveer una explicación de las condiciones históricas y los conflictos en que ellas surgen y evolucionan » (Juan R. VALDEZ, «Samaná (República Dominicana): ¿Baluarte del criollismo caribeño o cambio de contacto lingüístico cultural?», Estudios 18:35, Samaná (República Dominicana), (Enero-Julio 2010), p 30).

28. Cette carte géographique a été réalisée à partir d'un fond de carte localisé sur un site internet : $\quad$ http://betaeconomia.blogspot.com/2017/11/5-pasos-para-crear-mapas-derepublica.html.

29. John M. LIPSKI, El español de América, Madrid, Ediciones Cátedra (grupo Anaya, S.A.), 1996, 2014, p. 363 ; Almeida Jacqueline TORIBIO, « Nosotros somos dominicanos: Language and SelfDefinition among Dominicans ", Research on Spanish in the U.S., ed. Ana Roca, Somerville, MA : Cascadilla Press, (2000b), p. 253 ; Carlisle GONZÁLEZ TAPIA, «El español dominicano, un estudio diatópico de "R" y “L”", Anuario de Lingüística Hispánica, vol. 6, (1990), p. 226.

30. Carlisle GONZÁLEZ TAPIA, ibid.., p. 231.

31. Cf. Orlando ALBA, Variación fonética y diversidad social en el español dominicano de Santiago, Santiago, Pontificia Universidad Católica Madre y Maestra, 1990; Andre KLUMP, La dominicanidad de los dominicanos en RD, EE.UU. y España. Conferencia en línea, Centro de 
Estudios Europeos, Escuela de Humanidades y Ciencias Sociales de la Pontificia Universidad Católica Madre y Maestra (PUCMM), República Dominicana, 27 de octubre de 2020, p. 2, <URL; https://investigacion.pucmm.edu.do/estudios-europeos/Documents/Conferencia-PUCMM-

Klump.pdf> ; Pedro HENRÍQUEZ UREÑA, El español en Santo Domingo, (Instituto de Filología de la Universidad de Buenos Aires: Biblioteca de Dialectología Hispanoamericana, t.v.), Buenos Aires, Casa editora Coni, 1940, p. 38.

32. Almeida Jacqueline TORIBIO, « Nosotros somos dominicanos: Language and Self-Definition among Dominicans ", Research on Spanish in the U.S., ed. Ana Roca, Somerville, MA: Cascadilla Press, (2000b), p.253.

33. En prenant en compte les propos d'Orlando Alba, ce schéma est bien justifié : « No se debe olvidar que, con frecuencia, lo que hace distinta a una realidad de otra, no es la totalidad de los elementos que la componen, sino uno o dos detalles particulares presenten en la superficie [...] unos cuantos fenómenos se encargan de señalar la diferencia " (Orlando ALBA, La identidad lingüística de los dominicanos, Santo Domingo, Ediciones Librería La Trinitaria, Brigham Young University, 2009).

34. Bien que ce trait soit attribué aux locuteurs de la capitale, il fait partie aussi des parlers des zones rurales, comme le signale Román : «En la actualidad, en Sto. Domingo, la neutralización tanto diatópica como diastrática está muy extendida entre los campesinos. Este hecho se podía comprobar en el siglo XVIII : "por los mercadeles jinobeses”, "el Mercadel y el tahul “, "imitando en lo pelegrino" » (Mercedes ROMÁN FERNÁNDEZ, El español dominicano en el siglo XVIII. Análisis lingüístico de la historia de la conquista de la isla Española de Sto. Domingo de L. J. Peguero, Anejo n.․ IX de la Revista Cuadernos de Filología, Valencia, 1994, p. 105). Et elle ajoute : «Se puede decir que todos estos rasgos tienen una manifestación en el siglo XVI y que los hablantes del Mediodía español los llevaron hasta América » (Mercedes ROMÁN FERNÁNDEZ, El español dominicano en el siglo XVIII. Análisis lingüístico de la historia de la conquista de la isla Española de Sto. Domingo de L. J. Peguero, Anejo n.․ IX de la Revista Cuadernos de Filología, Valencia, 1994, p. 103).

35. Cf. D. Lincoln CANFIELD, Spanish pronunciation in the Américas, Chicago, University of Chicago Press, 1981 p. 47; cité dans John M. LIPSKI, El español de América, Madrid, Ediciones Cátedra (grupo Anaya, S.A.), 1996, 2014, p. 363.

36. Cf. William MEGENNEY, África en Santo Domingo: la herencia lingüística, Santo Domingo, Museo del Hombre Dominicano, 1990 ; cité dans (Id.).

37. Ce sont des plantations de canne à sucre où les journaliers haïtiens travaillent à la récolte de la canne et où ils séjournent. Au fil du temps, ces bateyes sont devenus lieux de résidence permanents pour ceux qui restent dans le pays ( $c f$. Ariel Osvaldo TAPIA MEDINA, "Unilinguisme vs plurilinguisme : le cas de la République Dominicaine", op. cit.).

38. Au niveau intralinguistique.

39. Nelson ROJAS, «Sobre la semivocalización de las líquidas en el español cibaeño», Orlando Alba (ed.), El español del Caribe. Ponencias del VI Simposio de dialectología, Santiago de los caballeros, Universidad Católica madre y Maestra,1982, p. 272.

40. Carlisle GONZÁLEZ TAPIA, «El español dominicano, un estudio diatópico de "R" y "L"», op. cit., p. 231.

41. Cf. Orlando ALBA, Variación fonética y diversidad social en el español dominicano de Santiago, op. cit.

42. Carlisle GONZÁlEZ TAPIA, ibid., p. 227.

43. VALDEZ, Juan R., «Samaná (República Dominicana): ¿Baluarte del criollismo caribeño o cambio de contacto lingüístico cultural?», Estudios 18:35, Samaná (República Dominicana), (enerojulio 2010), p. 39 ; Cf. Pablo GOLIBART, «Orígenes de la vocalización en el habla cibaeña», Eme Eme: Estudios Dominicanos, 4(22), Santiago, Universidad Católica Madre y Maestra (UCMM), 1976, p. 127-144 <URL : https://dloc.com/PUCMMA0011/00040/5j>. 
44. Pablo GOLIBART, «Orígenes de la vocalización en el habla cibaeña», Eme Eme: Estudios Dominicanos, 4(22), Santiago, Universidad Católica Madre y Maestra (UCMM), (1976), p. 135 <URL: https://dloc.com/PUCMMA0011/00040/5j>.

45. Raymond MCCURDY, The Spanish Dialect of St. Bernard Paris, Louisiana. Alburquerque : The University of New Mexico Press, (1950), p. 34 ; cité dans Pablo GOLIBART, "Orígenes de la vocalización en el habla cibaeña", Eme Eme: Estudios Dominicanos, 4(22), Santiago, Universidad Católica Madre y Maestra (UCMM), (1976), p. 136.

46. Manuel ÁlVAREZ NAZARIO, La Herencia Lingüística de Canarias en Puerto Rico, Barcelona: M. Pareja. 1972, p. 68, cité dans Pablo GOLIBART, "Orígenes de la vocalización en el habla cibaeña", Eme Eme: Estudios Dominicanos, 4(22), Santiago, Universidad Católica Madre y Maestra (UCMM), (1976), p. $136<$ URL : https://dloc.com/PUCMMA0011/00040/5j>.

47. Pablo GOLIBART, "Orígenes de la vocalización en el habla cibaeña", Eme Eme: Estudios Dominicanos, 4(22), Santiago, Universidad Católica Madre y Maestra (UCMM), (1976), p. $127<$ URL : https://dloc.com/PUCMMA0011/00040/5j>.

48. Id.

49. Andre KLUMP, La dominicanidad de los dominicanos en RD, EE.UU. y España. Conferencia en línea, Centro de Estudios Europeos, Escuela de Humanidades y Ciencias Sociales de la Pontificia Universidad Católica Madre y Maestra (PUCMM), República Dominicana, 27 de octubre de 2020 <URL: $\quad$ https://investigacion.pucmm.edu.do/estudios-europeos/Documents/ConferenciaPUCMM-Klump.pdf>.

50. Pour différencier le degré de discrimination parmi les communautés linguistiques dominicaines, il faut distinguer les concepts de stéréotype et de stigmate, comme l'explique José Luis Blas Arroyo : « [...] los estereotipos son, pues, marcadores sociolingüísticos que la comunidad reconoce como tales. Por otro lado, se consideran como rasgos definitorios del habla de ciertos grupos sociales que se consideran de escaso prestigio social (clases bajas, grupos étnicos marginados, etc.), que, además, se perciben -erróneamente- no como elementos variables, sino categóricos» (José Luis BLAS ARROYO, Sociolingüística del español. Desarrollo y perspectivas en el estudio de la lengua española en contexto social, Madrid, Ediciones Cátedra (Grupo Anaya, S.A), 2005, 2012, p. 137).

51. Voir le poème de Juan ANTONIO ALIX, «Un Campesino dominicano que estuvo en Haití vendiendo unos andullos y a su regreso tuvo una entrevista muy curiosa ", Décimas / Juan Antonio Alix; prólogo: José R. López, Santo Domingo, Imprenta de J. R. Vda. García, 1927, où le parler des cibaeños est bien stéréotypé conjointement avec celui de le Haïtien.

52. John M. LIPSKI, El español de América, Madrid, Ediciones Cátedra (grupo Anaya, S.A.), 1996, 2014, p. 363.

53. Jacqueline Almeida TORIBIO « Language variation and the linguistic enactment of identity among Dominicans ", Linguistics 38-5, (2000a), p. 1136.

54. Orlando ALBA, La identidad lingüística de los dominicanos, op. cit., p. 17.

55. Dans cette situation : «La variante lateralizada de / /, es decir, la neutralización de / $/$ en /l/ parece ser un rasgo de reciente aparición que no está estigmatizado en el español de Santiago (Orlando ALBA, Variación fonética y diversidad social en el español dominicano de Santiago, op. cit., cité dans Carlisle GONZÁLEZ TAPIA, Estudio sobre el habla culta dominicana (resultados parciales de una investigación). Con un estudio especial de los idiolectos de Bosch y Balaguer, Santo Domingo, Editora universitaria -UASD, 1994, p. 15). En conséquence il y a une prépondérance à considérer cette variante en tant que prestigieuse dans le style soigné de cette ville. Mais à l'instar des capitaleños avec la latéralisation (Manuel ALVAR, El español en la República Dominicana. Estudios, encuestas, textos, Alcalá de Henares, Universidad de Alcalá. Servicios de Publicaciones, La Goleta Ediciones, 2000, pp. 26-27), les cibaeños expriment aussi une grande solidarité envers leur propre variante. De plus, ce sentiment d'infériorité est surmonté par celui de la solidarité ou de la loyauté (Orlando ALBA, La identidad lingüística de los dominicanos,op. cit., p. 71). 
56. Ibid.

57. Jacqueline Almeida TORIBIO « Language variation and the linguistic enactment of identity among Dominicans », Linguistics 38-5 (2000a), p. 1143.

58. Id.

59. Traduction : «La loyauté linguistique dans la diaspora dominicaine est un indicateur fort que le dialecte dominicain est une caractéristique importante de l'identité ethnique dominicaine » (Almeida Jacqueline TORIBIO, « Nosotros somos dominicanos: Language and Self-Definition among Dominicans ", Research on Spanish in the U.S., ed. Ana Roca, Somerville, MA : Cascadilla Press, (2000b), p. 265).

60. « Today, about one million Dominicans reside in the U.S, concentrated predominantly along the eastern seaboard with an estimated $69 \%$ in N.Y ». Traduction : «Actuellement, environ un million de Dominicains resident aux États-Unis, concentrés principalement le long du littoral oriental avec un environ 69 \% d'habitants à New York » (Almeida Jacqueline TORIBIO, « Nosotros somos dominicanos: Language and Self-Definition among Dominicans ", Research on Spanish in the U.S., ed. Ana Roca, Somerville, MA : Cascadilla Press, (2000b), p. 262).

61. C'est ainsi que «The continued use of the Dominican vernacular is a strong indicator that the immigrant community considers its language to be an important feature to its identity, a positive assertion of dominicanidad» Traduction : «L'utilisation continue de la langue vernaculaire est un indicateur fort $\mathrm{du}$ fait que la communauté immigrée considère sa langue comme une caractéristique importante de son identité, une affirmation positive de sa dominicanidad» (Almeida Jacqueline TORIBIO, " Nosotros somos dominicanos: Language and Self-Definition among Dominicans », op. cit., p. 261).

62. Carlisle GONZÁLEZ TAPIA, «El español dominicano, un estudio diatópico de "R" y "L"», op. cit., p. 229.

63. Andre KLUMP, La dominicanidad de los dominicanos en RD, EE.UU. y España. Conferencia en línea, Centro de Estudios Europeos, Escuela de Humanidades y Ciencias Sociales de la Pontificia Universidad Católica Madre y Maestra (PUCMM), República Dominicana, 27 de octubre de 2020 <URL : $\quad$ https://investigacion.pucmm.edu.do/estudios-europeos/Documents/ConferenciaPUCMM-Klump.pdf>.

64. Orlando ALBA, La identidad lingüística de los dominicanos, op. cit., p. 29.

65. Ibid.

66. Andre KLUMP, La dominicanidad de los dominicanos en RD, EE.UU. y España. Conferencia en línea, Centro de Estudios Europeos, Escuela de Humanidades y Ciencias Sociales de la Pontificia Universidad Católica Madre y Maestra (PUCMM), República Dominicana, 27 de octubre de 2020 <URL : $\quad$ https://investigacion.pucmm.edu.do/estudios-europeos/Documents/ConferenciaPUCMM-Klump.pdf>.

Orlando ALBA, La identidad lingüística de los dominicanos, op. cit., p. 29.

67. Carlisle GONZÁLEZ TAPIA, «El español dominicano, un estudio diatópico de "R" y "L"», op. cit., p. 231.

68. Andre KLUMP, La dominicanidad de los dominicanos en RD, EE.UU. y España. Conferencia en línea, Centro de Estudios Europeos, Escuela de Humanidades y Ciencias Sociales de la Pontificia Universidad Católica Madre y Maestra (PUCMM), República Dominicana, 27 de octubre de 2020 <URL : $\quad$ https://investigacion.pucmm.edu.do/estudios-europeos/Documents/ConferenciaPUCMM-Klump.pdf>.

69. En fait, c'est le phénomène le plus représentatif du parler dominicain, réalisé, surtout, par la jeunesse des quartiers modestes de la capitale dominicaine. Toutefois, de nos jours, ce phénomène touche tous les sociolectes et au niveau national, représente une marque de prestige et, vu de l'extérieur, une marque diatopique propre à la Caraïbe hispanique.

70. Cf. Ariel Osvaldo TAPIA MEDINA, "Hacia una nueva conciencia sociolingüística: afrodominicanismo y el habla dominicana" ", dans Jean-Arsène Yao (coord.), Áfricas, Américas y 
caribes. Representaciones colectivas cruzadas [siglos XIX-XXI], Alcalá de Henares, Universidad de Alcalá de Henares publicaciones, 2020, pp. 319-325.

71. Juan R. VALDEZ, "La regimentación lingüística en un escenario transnacional La República Dominicana / Haití”, Language Problems and Language Planning, Vol. 38:2, (2014), p. 170 ; Orlando ALBA, La identidad lingüística de los dominicanos, op. cit., p. 17.

72. Rafael A. NÚÑEZ CEDEÑO, La fonología Moderna y el español de Santo Domingo, Santo Domingo, Editora Taller, 1980, p. 229.

73. Id..

74. John M. LIPSKI, El español de América, Madrid, Ediciones Cátedra (grupo Anaya, S.A.), 1996, 2014 , p. 363.

75. Seconde langue.

76. Ibid.

77. Pedro HENRÍQUEZ UREÑA, El español en Santo Domingo, (Instituto de Filología de la Universidad de Buenos Aires: Biblioteca de Dialectología Hispanoamericana, t.v.), Buenos Aires, Casa editora Coni, 1940, p. 38.

78. Ibid.

79. Juan R. VALDEZ, «La regimentación lingüística en un escenario transnacional La República Dominicana / Haití», Language Problems and Language Planning, Vol. 38:2, (2014), p. 171.

80. Juan R. VALDEZ, «Samaná (República Dominicana): ¿Baluarte del criollismo caribeño o cambio de contacto lingüístico cultural?», Estudios 18:35, Samaná (República Dominicana) (Enero Julio 2010), p. 42.

81. Ibid.

82. Dans cet article on a pris en tant que modèle, pour ces isoglosses sous-jacentes, les bateyes de La libertad et Cerro gordo qui ont été prises comme objet d'étude par Rosas MAYÉN NORMA, «Las consonantes líquidas en el kreyñol, una variedad del español afrodominicano», Dialectología 12 (2014), pp. 109-130.

83. Juan R. VALDEZ, «La regimentación lingüística en un escenario transnacional La República Dominicana / Haití», Language Problems and Language Planning, Vol. 38:2,( 2014), p. 150.

84. Cette carte dialectologique a été réalisée à partir d'un fond de carte localisé sur site internet : http://betaeconomia.blogspot.com/2017/11/5-pasos-para-crear-mapas-de-republica.html.

85. Louis-Jean CALVET, «Des frontières et des langues». Entretien avec Thierry Paquot, Marseille", Hermès, La Revue, n63, C.N.R.S Éditions, (2012/2), p. 51 à 56 <URL: https:// www.cairn.info/revue-hermes-la-revue-2012-2-page-51.htm 2012, p. 2. Eva Gugenberger affirme, elle aussi, cette réalité : «Las fronteras lingüisticas nunca son fronteras nítidas, más bien son construcciones hechas por los seres humanos » (Eva GUGENBERGER «El castellano y las lenguas regionales en España: Bilingüismo e hibridación», La España multilingüe, Viena: Praesens Verlag, Cichon, P., Doppelbauer, M., (eds.), 2008, pp. 31-52, p. 34).

86. Id..

87. Cette carte interlinguistique a été réalisée à partir d'un fond de carte localisé sur site internet : $\quad$ http://betaeconomia.blogspot.com/2017/11/5-pasos-para-crear-mapas-derepublica.html.

88. Principalement pendant l'occupation haïtienne (1882-1844), à la fin du XIX siècle et après de la dictature de Trujillo en tant que migrants économiques.

89. Cf. Rosas MAYÉN NORMA, "Las consonantes líquidas en el kreyñol, una variedad del español afrodominicano", Dialectología 12 (2014), p. 109-130.

90. Carlisle GONZÁLEZ TAPIA et Benavides CELSO, “Existen rasgos criollos en el habla de Samaná?”, El español del Caribe. Ponencias del VI Simposio de Dialectología. Orlando Alba editor, Santiago de los Caballeros, 1981, p. 106.

91. Ibid.

92. C'est le créole haïtien, nommé ainsi de manière péjorative. 
93. De cette pratique glottopolitique découle la notion de l'unilinguisme, c'est-à-dire, «l'unification linguistique du territoire dans ses deux orientations solidaires : interlinguistique et intralinguistique» (Henri, BOYER «Idéologie sociolinguistique et politiques linguistiques (intérieures) de la France ». Synergies. Pays germanophones, $(2012,5)$, p. 1 et 5). À peine est-il fait référence à ce bilinguisme créole-espagnol parmi les dominicains dans les études linguistiques réalisées par les socio(ethno)linguistes dominicains (Silke JANSEN, «Monolingüismo y bilingüismo en el discurso de la lingüística hispánica», Aspectos del desarrollo de la lingüística española a través de los siglos, Hamburgo: Verlag, K. Wieland, K. Süselbeck y V. Eilers (eds.), 2010, p. 5). «L'unification d'une communauté linguistique se fait à deux niveaux : linguistiquement et politiquement » (ENCREVÉ Pierre, « Présentation », dans William LABOV, Sociolinguistique, Paris, pour la traduction by Les éditions de Minuit, 1976, p. 32). Alors ce dernier a joué le rôle le plus important dans l'aménagement du paysage linguistique en République Dominicaine.

94. Silke JANSEN, «Monolingüismo y bilingüismo en el discurso de la lingüística hispánica», Aspectos del desarrollo de la lingüística española a través de los siglos, Hamburgo: Verlag, K. Wieland, K. Süselbeck y V. Eilers (eds.), 2010, p. 2.

95. Frank Marino HERNÁNDEZ, «La inmigración haitiana en la República Dominicana», Eme-Eme, volumen I, 5 marzo-abril (1973), p. 29 <URL : https://dloc.com/PUCMMA0011/00040/5j>.

96. On tend à oublier que nous avons eu un président d'origine haïtienne, selon le récit de $\mathrm{R}$. Michael Malek : « Heureaux decía que había nacido en Puerto Plata el 21 de octubre de 1845 hijo ilegítimo de un haitiano llamado D’Assas Heureaux y de una negra de Saint Thomas llamada Josefa Level. Había quienes, sin embargo, afirmaban que Heureaux había nacido en la isla de Saint Thomas y no era dominicano por nacimiento. Aún su nacimiento está rodeado de misterio » (Michael MALEK, «El régimen de Ulises Heureaux: 1882-1899, desarrollo y dictadura en la República Dominicana», Eme-Eme: Estudios Dominicanos, 11(65), (1983, p. 38) <URL: https:// dloc.com/PUCMMA0011/00040/5j>.

Paradoxalement, Ulises Heureaux eut une influence très importante - en tant qu'homme politique - chez Trujillo. Pourtant il a redéfini la nationalité dominicaine - comme bien indiqué par Robert Cassá - «sobre una base hispánica, racista y antihaitiana (María Filomena GONZÁLEZ y Rubén SILIÉ, «La nación dominicana en la enseñanza de la historia a nivel primario», Eme-Eme Estudios Dominicanos, Volumen XIV, número 79 julio/agosto, (1985, p.18) <URL : https://dloc.com/PUCMMA0011/00040/5j>.

Par conséquent, les intellectuels sont unanimes concernant le lien entre sentiment et culture hispaniques : « el sentimiento de hispanidad del dominicano ha sido más fuerte que la percepción de la raza» d'après Frank Moya Pons (Carlos DOBAL, «Hispanidad y Dominicanidad», Santiago: Eme-Eme Estudios Dominicanos, vol. XII no 72 mayo/junio, 1984, p. 91)<URL : https:// dloc.com/PUCMMA0011/00040/5j>.

C'est ainsi que «La identidad asociada al color de la piel también se hace extensiva al tema del origen del pueblo dominicano. Siguiendo la encuesta, para más de la mitad (54\%) de los habitantes del país la procedencia del pueblo dominicano es el resultado de una mezcla » (Ana Féliz LAFONTIANE, «La Identidad Cultural Dominicana: Más allá de los discursos esencialistas», Perspectivas, № 05-17, (2017), p. 5). C'est pourquoi Emilio Rodriguez Demorizi affirme que « el color no bastaba en algunas ocasiones. La lengua fue entonces la señal distintiva » (Emilio RODRÍGUEZ DEMORIZI, Lengua y folklore de Santo Domingo. Santiago, República Dominicana, (primera edición), Universidad Católica Madre y Maestra, 1975, p. 21).

97. Par les traités de Ryswick (1967) et celui de Bâle (1975).

98. Ana Féliz LAFONTAINE, «La Identidad Cultural Dominicana: Más allá de los discursos esencialistas», Perspectivas, № 05-17, (2017), p. 3.

99. Selon le degré de discrimination que remarque Blas Arroyo : «ocasionalmente, se distingue un cuarto tipo de variable sociolingüística, a la que se denomina, significativamente, estigma, que representaría un estadio avanzado del estereotipo » (José Luis BLAS ARROYO, Sociolingüística del 
español. Desarrollo y perspectivas en el estudio de la lengua española en contexto social, Madrid, Ediciones Cátedra (Grupo Anaya, S.A), 2005, 2012, p. 37).

100. Antonio LLUBERES NAVARRO, «Caribe, Azúcar y Migración, 1789-1944», Santiago: Eme-Eme Estudios Dominicanos, volumen II número 39,( noviembre-diciembre 1978), p. $38<\mathrm{URL}$ : https:// dloc.com/PUCMMA0011/00040/5j>.

101. Federico HENRÍQUEZ GRATEREAUX, «Negros de mentira y blancos de verdad», Santiago, Eme-Eme Estudios Dominicanos, vol. XV nº 81, (sep./dic., 1988), p.74<URL : https://dloc.com/ PUCMMA0011/00083/75j>.

102. Orlando ALBA, «A propósito de la identidad lingüística dominicana », Santiago: Eme-Eme Estudios Dominicanos, vol. XII, $\mathrm{n}^{\circ} 72$, (mayo-junio 1984), p. 31.

103. John M. LIPSKI, El español de América, Madrid, Ediciones Cátedra (grupo Anaya, S.A.), 1996, 2014, p. 360.

104. Patrick CHARAUDEAU, «Identité linguistique, identité culturelle: Une relation paradoxale », Christian Lagarde (Éd.), Le discours sur les «langues d'Espagne» 1978-2008, Perpignan, Presses Universitaires de Perpignan, 2009, p. 26.

105. Victorien LAVOU ZOUGNBO, "Métissage et créolisation. Questionnements et contrepoint », dans Jean-Arsène Yao (coord.), Áfricas, Américas y caribes. Representaciones colectivas cruzadas (siglos XIX-XXI), Alcalá de Henares, Universidad de Alcalá de Henares publicaciones, 2020, p. 143-155.

106. La réalité est néanmoins bien distincte, la variation d'un seul et unique phonème inclut ou exclut d'une identité donnée.

107. En finissant la rédaction de cet article j'ai appris la triste nouvelle selon laquelle le gouvernement dominicain a annoncé la construction d'un mur entre la République Dominicaine et Haïti. Source : RT Español <URL : https://www.youtube.com/watch?v=t6ldF9tiD9Y>.

\section{RÉSUMÉS}

L'identité dominicaine a toujours été associée à la langue espagnole. Bien qu'il y ait d'autres éléments culturels qui - tels que la religion ou l'Histoire - pourraient aussi bien représenter la culture dominicaine, c'est toujours la langue qui trône dans cette démarche identitaire. Or, son choix n'est pas anodin car le fait de prendre la langue comme artefact symbolique manifeste une volonté politique d'invisibiliser, d'un côté, les autres sous-variantes du territoire - ainsi que d'autres variantes, que l'on peut appeler «sous-jacentes»- et de l'autre côté, de créer une barrière symbolique et réelle entre l'espagnol et les autres langues parlées à l'intérieur du pays. Dans cet article on va essayer de déterminer les autres identités linguistiques invisibilisées de la nation dominicaine à partir de l'analyse de son écosystème intralinguistique et interlinguistique.

The Dominican identity has always been associated with the Spanish language. Although there are other cultural elements that - such as religion or History - might as well represent Dominican culture, it is still the language that dominates this identity process. However, his choice is not trivial because the fact of taking the language as a symbolic artefact manifests a political will to invisibilize, on the one hand, the other sub-variants of the territory - and as well of the other variants, that the one can call, " underlying " - and on the other hand, to create a symbolic and real barrier between Spanish and the other languages spoken within the country. In this article we will try to determine the other invisibilized linguistic identities of the Dominican nation from the analysis of its intralinguistic and interlinguistic ecosystem. 
INDEX

Mots-clés : isoglosses, variation diatopique, enclaves linguistiques, identités, barrières linguistiques

Keywords : isoglosses, diatopic variation, linguistic enclaves, identities, linguistics barriers

\section{AUTEUR}

ARIEL OSVALDO TAPIA MEDINA

Université de Perpignan - Via Domitia 